\title{
INFLUENCE OF PHARMACISTS' INTERVENTION ON DRUG-RELATED PROBLEMS RELATED TO CHANGE IN HEMOGLOBIN LEVELS OF HEMODIALYSIS PATIENTS AT ADJIDARMO HOSPITAL, LEBAK, BANTEN
}

\author{
AI YENI HERLINAWATI, RANI SAURISARI*, RETNOSARI ANDRAJATI
}

Department of Pharmacy, Faculty of Pharmacy, Universitas Indonesia, Depok, Indonesia. Email: rani@farmasi.ui.ac.id Received: 21 April 2017, Revised and Accepted: 13 July 2017

ABSTRACT

Objective: This study aims to evaluate the intervention of pharmacists for drug-related problems (DRPs) related to hemoglobin (Hb) level.

Methods: This study uses a prospective pre-experimental and pre-post design. The study sample included 85 patients. All patients were interviewed, and their prescriptions were identified. Then, interventions were given to doctors and patients based on the identified DRPs. Univariate, bivariate, and multivariate data analysis with binary logistic regression analysis were used.

Results: There was a significant decrease $(\mathrm{p}<0.05)$ in the number of DRPs before $(2.85 \pm 1.82)$ and after $(0.74 \pm 0.86)$ the intervention. There was also a significant increase $(p<0.05)$ in the average $\mathrm{Hb}$ level before $(9.29 \pm 1.39)$ and after $(9.68 \pm 1.41)$ the intervention; the average increase in Hb level after the intervention was $0.39 \mathrm{~g} / \mathrm{dl}$. DRP significantly influences the changes in $\mathrm{Hb}$ level after the intervention. Hb level increased by 0.145 times after intervention (odds ratio $=0.145$, $\mathrm{p}=0.015$ ).

Conclusions: Pharmacists' intervention for DRPs can increase the success of anemia therapy of hemodialysis patients at Adjidarmo Hospital, Lebak, Banten.

Keywords: Hemoglobin, Drug-related problem, Hemodialysis.

(c) 2017 The Authors. Published by Innovare Academic Sciences Pvt Ltd. This is an open access article under the CC BY license (http://creativecommons. org/licenses/by/4. 0/) DOI: http://dx.doi.org/10.22159/ajpcr.2017.v10s5.23113

\section{INTRODUCTION}

Anemia in chronic kidney disease (CKD) patients is mainly caused by a decrease in erythropoietin and iron deficiency [1]. According to the USRDS 2010 data, in the United States, the prevalence of anemia in CKD patients at Stages 1-4 was 51.8\%, and the average hemoglobin ( $\mathrm{Hb})$ level in CKD patients was $9.9 \mathrm{~g} / \mathrm{dl}$. In 2010, at Cipto Mangunkusumo Hospital, Jakarta, anemia was found in $100 \%$ of patients who first came for hemodialysis, with an average $\mathrm{Hb}$ level of $7.7 \mathrm{~g} / \mathrm{dl}$ [2]. CKD patients experience iron deficiency anemia usually due to insufficient nutrition, absorption disturbances, chronic bleeding, inflammation, or infection [1]. Male and female patients were considered anemic if their $\mathrm{Hb}$ level was $<13$ and $<12 \mathrm{~g} / \mathrm{dl}$, respectively [2].

CKD patients usually have comorbidities that may increase their morbidity and mortality; these include anemia, heart failure, hypertension, and fluid and electrolyte disturbances [3]. Anemia causes an increase in morbidity, mortality, and number of hospital treatments. It also decreases the quality of life, systemic hemodynamics and function of heart capacity, and cognitive ability and increases the prevalence of left ventricle enlargement [4].

In 2015, around 100 CKD patients were undergoing hemodialysis at Adjidarmo Hospital, Lebak, Banten. On average, there were 800 patient visits a month, with around 700 sheets of drug prescriptions. At this hospital, no pharmacists were active in the hemodialysis room, and therefore, the participation and intervention of pharmacists were required to reduce the number of drug-related problems (DRPs) and to minimize the risks of drugs. This study investigates the influence of pharmacists' intervention in reducing DRPs by identifying and preventing them.

\section{METHODS}

This study used a pre-experimental and pre-post design.
The independent variable in this study is the pharmacists' intervention through recommendations; the dependent variable is the $\mathrm{Hb}$ level, where the number of DRPs acts as an intervening variable; and the confounding variable is the CKD stage and frequency of hemodialysis [1].

The study population included 130 CKD patients in the Hemodialysis Outpatient Clinic of Adjidarmo Hospital, Lebak, Banten, from December 2016 to May 2017. The study sample included CKD outpatients at this hospital during the same time period that fits the inclusion criteria.

The inclusion criteria were as follows: Patients who had the same prescriptions before and after intervention at the Hemodialysis Outpatient Clinic of Adjidarmo Hospital, Lebak, Banten, from November 2016 to January 2017; CKD patients who underwent $\mathrm{Hb}$ testing before and after intervention; and adult patients (age $>20$ years) who were willing to participate in this study. The exclusion criteria were as follows: Patients with incomplete or unusable medical records and patients with incomplete drug therapy data for evaluating DRP. The drop-out criterion was patients who dropped out of the experiment.

Based on the previous calculations, the minimum sample size required for this experiment is 75 patients. The researcher selected 85 patients in the sample. All patients were interviewed, and the study objectives were explained to them. Patients who were willing to participate in this study provided informed consent. Then, secondary data obtained from medical records were recorded, including age, gender, CKD stage, weekly frequency of hemodialysis, comorbidities, number of drug therapies, nutrition status, and $\mathrm{Hb}$ level before the intervention. The intervention was given to doctors and patients based on the identified DRP. The intervention results were evaluated using the Pharmaceutical Care Network Europe (PCNE) 6.2.2010, and the DRP and Hb levels were reevaluated after intervention. All data were analyzed and evaluated using SPSS 23.0 


\section{RESULTS}

The sociodemographic characteristics of CKD patients that fit the inclusion criteria are shown in Table 1. There were more female patients $(52.9 \%)$ than male patients $(47.1 \%)$. This was also not in accordance with the literature stating that more CKD patients were male [5]. This was attributable to the different location from which the study sample was taken, as shown in Fig. 1. Wilcoxon's test showed that the average mean scores of DRPs before $(2.85 \pm 1.82)$ and after $(0.74 \pm 0.86)$ the intervention were significantly different $(\mathrm{p}<0.05)$, as shown in Table 2 and Fig. 2.

The 85 patients in the study sample (Table 3) received 1073 drug therapies. After DRPs associated with Hb levels were identified, they were classified based on the PCNE 6.22010 classification as follows [6]: Problem 1 (P1)=Effective therapy, and Problem 2 (P2)=Unwanted drug reaction. Among the 59 drugs used by CKD patients undergoing hemodialysis, 13 caused DRPs associated with Hb levels. DRPs were categorized as DRP $\leq 1$ and DRP $\geq 2$. The intervention was given to

Table 1: Sociodemographic characteristics of hemodialysis patients $(n=85)$

\begin{tabular}{ll}
\hline Characteristic & Number of patients (\%) \\
\hline Age & \\
$\quad<60$ years & $65(76.5)$ \\
$\geq 60$ years & $20(23.5)$ \\
Gender & \\
$\quad$ Male & $40(47.1)$ \\
Female & $45(52.9)$ \\
\hline
\end{tabular}

Table 2: Average mean scores of DRPs before and after intervention (Wilcoxon's test)

\begin{tabular}{llll}
\hline DRP & Before intervention & After intervention & p value \\
\hline Score & $2.85 \pm 1.82$ & $0.74 \pm 0.86$ & 0.000 \\
\hline DRP: Drug-related problems & &
\end{tabular}

Table 3: Hb characteristics of hemodialysis patients ( $n=85$, Chi-square test)

\begin{tabular}{|c|c|c|c|c|}
\hline Characteristic & $\begin{array}{l}\text { Number of } \\
\text { patients } \\
\text { before (\%) }\end{array}$ & $\begin{array}{l}\text { Number of } \\
\text { patients } \\
\text { after (\%) }\end{array}$ & $\begin{array}{l}\text { p value } \\
\text { DRP }\end{array}$ & $\begin{array}{l}\text { p value } \\
\mathrm{Hb}\end{array}$ \\
\hline \multicolumn{5}{|l|}{ CKD stage } \\
\hline $\mathrm{LFG}>15 \mathrm{ml} / \mathrm{min}$ & $6(7.1)$ & $6(7.1)$ & 0.665 & 0.582 \\
\hline $\mathrm{LFP} \leq 15 \mathrm{ml} / \mathrm{min}$ & $79(92.9)$ & $79(92.9)$ & & \\
\hline \multicolumn{5}{|l|}{$\begin{array}{l}\text { Hemodialysis } \\
\text { schedule }\end{array}$} \\
\hline Once a week & $9(10.6)$ & $9(10.6)$ & 0.644 & 0.396 \\
\hline Twice a week & $76(89.4)$ & $76(89.4)$ & & \\
\hline \multicolumn{5}{|l|}{ Comorbidities } \\
\hline$\leq 1$ & $2(2.4)$ & $29(34.1)$ & 0.05 & 0.286 \\
\hline$\geq 2$ & 83 (97.6) & $56(65.8)$ & & \\
\hline \multicolumn{5}{|l|}{$\begin{array}{l}\text { Number of drug } \\
\text { therapies }\end{array}$} \\
\hline$\leq 7$ & $2(2.35)$ & $2(2.35)$ & 0.05 & 0.584 \\
\hline$\geq 8$ & $83(97.64)$ & $83(97.64)$ & & \\
\hline \multicolumn{5}{|l|}{$\begin{array}{l}\text { Good nutritional } \\
\text { status }\end{array}$} \\
\hline Yes & $62(72.9)$ & $62(72.9)$ & 0.261 & 0.000 \\
\hline No & $23(27.11)$ & $23(27.1)$ & & \\
\hline
\end{tabular}

CKD: Chronic kidney disease, Hb: Hemoglobin, LFG:GFR: Gromerular filtration rate doctors and patients based on the identified DRP. Wilcoxon's test results indicated a significant difference $(p<0.05)$ between the mean $\mathrm{Hb}$ levels before and after the intervention, as shown in Table 4. Paired sample test results showed a significant increase $(\mathrm{p}<0.05)$ in mean $\mathrm{Hb}$ levels before $(9.29 \pm 1.39)$ and after $(9.68 \pm 1.41)$ the intervention (Fig. 3); $\mathrm{Hb}$ levels increase by an average of $0.39 \mathrm{~g} / \mathrm{dl}$ after the intervention. These results are shown in Table 5.

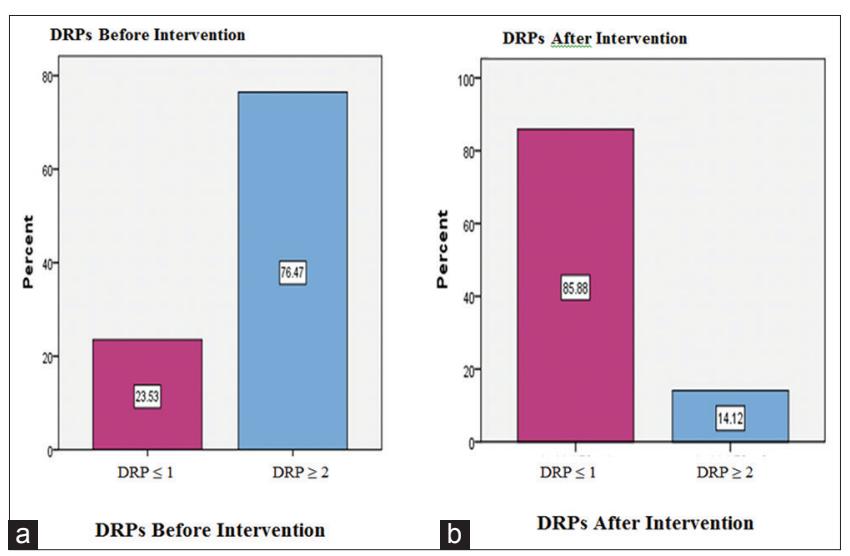

Fig. 2: (a-b) The changes in drug-related problems before and after the intervention

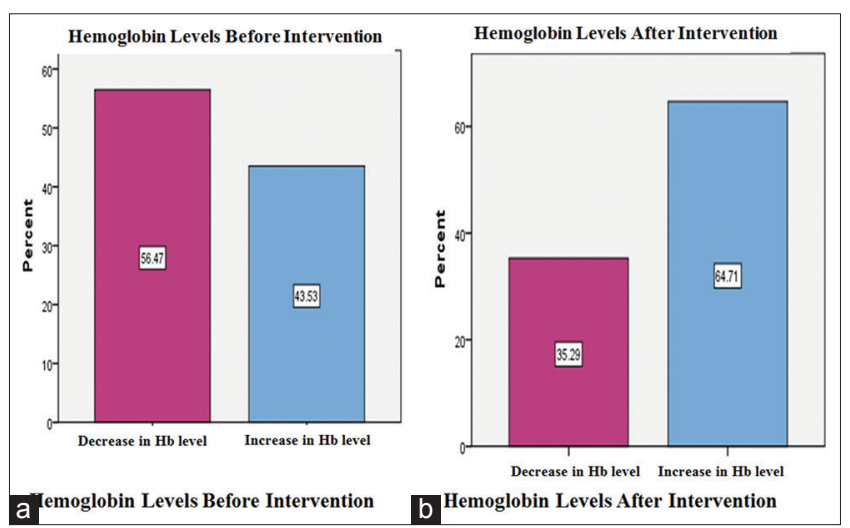

Fig. 3: ( $a$ and $b$ ) The change in hemoglobin levels before and after the intervention

Table 4: Difference in mean $\mathrm{Hb}$ levels before and after intervention for DRPs ( $n=85$, Wilcoxon's test)

\begin{tabular}{lllc}
\hline DRP & $\begin{array}{l}\text { Before } \\
\text { intervention (\%) }\end{array}$ & $\begin{array}{l}\text { After } \\
\text { intervention (\%) }\end{array}$ & p value \\
\hline$\leq 1$ & $20(23.5)$ & $73(85.9)$ & 0.000 \\
$\geq 2$ & $65(76.5)$ & $12(14.1)$ & \\
\hline DRP: Drug-related problems, Hb: Hemoglobin
\end{tabular}

DRP: Drug-related problems, Hb: Hemoglobin

Table 5: Difference in mean $\mathrm{Hb}$ levels before and after intervention (paired samples test)

\begin{tabular}{llll}
\hline Score & Before intervention & After intervention & p value \\
\hline Hb level & $9.29 \pm 1.39$ & $9.68 \pm 1.41$ & 0.000 \\
\hline
\end{tabular}

Hb: Hemoglobin

\begin{tabular}{|c|c|c|c|}
\hline $\begin{array}{l}\text { Number of DRP_Pre } \\
\text { Hemoglobin level_Pre }\end{array}$ & $=$ & $\begin{array}{l}\text { Pharmacist intervention } \\
\text { through recommendations }\end{array}$ & $\begin{array}{l}\Rightarrow \text { Number of DRP_Post } \\
\text { Hemoglobin level Post }\end{array}$ \\
\hline
\end{tabular}

Fig. 1: Experimental scheme 
A multivariate analysis was conducted to find the factor that most affected the Hb levels. The test used was the binary logistic regression analysis. The results showed that DRP had a significant effect on the change in $\mathrm{Hb}$ levels after intervention; specifically, the $\mathrm{Hb}$ levels increased by 0.145 times compared to those before the intervention $(\mathrm{OR}=0.145, \mathrm{p}=0.015)$

\section{DISCUSSION}

CKD patients undergoing hemodialysis usually receive around $12 \mathrm{drug}$ prescriptions. These prescriptions have a high risk of causing DRPs [5]. DRPs can occur owing to the patient's condition or because of the drugs themselves. Drug-related factors that can cause DRPs include nephrotoxicity, dosage, time of dosage, frequency, form, repeated exposure, and increase in a number of drugs, resulting in increased number of unwanted drug reactions and interactions. DRPs can disturb and cause a decrease in $\mathrm{Hb}$ levels and increase in ureum and creatinine plasma [7]. Pharmacists play a key role in identifying and preventing DRPs by conducting interventions with the doctor, patient, and nurse based on predicted DRPs [8]

DRPs associated with $\mathrm{Hb}$ levels were mostly caused by prescription, for example, calcium carbonate can reduce the absorption of ferrous sulfate. Therefore, it is recommended to keep an interval between the consumption of calcium carbonate and ferrous sulfate to avoid reducing the therapeutic efficacy of the latter. Monitoring of patients' Hb levels is recommended. The studies have noted that iron absorption can reduce by $60 \%$ when it is given with calcium carbonate [9]. Further, patients were given natrium bicarbonate tablets $(3 \times 1$ or $3 \times 2)$ immediately after a meal. Studies, however, have shown that it is best to administer oral drugs 1-3 hrs after a meal [10]. Therefore, patients were told to take the natrium bicarbonate tablets 1-3 hrs after their meal. Natrium bicarbonate can reduce the absorption of ferrous sulfate. Therefore, it is recommended to keep an interval between the consumption of natrium bicarbonate and ferrous sulfate to avoid reducing the therapeutic efficacy of the latter. Monitoring of patients' Hb levels is recommended.

\section{REFERENCES}

1. Price SA, Wilson LM. Pathophysiologi: Chlinical Concept of Disease Process. New York: McGraw-Hill; 2006.

2. De Benoist B, McLean E, Egly I, Cogswell M, editors. Worldwide Prevalence of Anaemia 1993-2005: WHO Global Database on Anaemia World Health Organization. Geneva: World Health Organization; 2008.

3. Taal MW. Progress in risk prediction for people with chronic kidney disease. Curr Opin Nephrol Hypertens 2014;23(6):519-24.

4. Perhimpunan Nefrologi Indonesia. Konsensus Manajemen Anemia Pada Penyakit Ginjal Kronik. $2^{\text {nd }}$ ed. Jakarta: Perhimpunan Nefrologi Indonesia; 2011.

5. Rani NV, Thomas R, Rohini E, Soundararajan P, Kannan G, Thennarasu $\mathrm{P}$, et al. A study on drug related problem in chronic kidney disease patients of tertiary care teaching hospital in South India. Faculty of Pharmacy. Chennai, India: Sri Ramachandra University; 2014.

6. Pharmaceutical Care Network Europe (PCNE) Foundation. PCNE Classification for Drug Related Problems. Vol. 6. PCNE; 2010. p. 2.

7. Salgado TM, Moles R, Benrimoj SI, Fernandez-Llimos F. Pharmacists' interventions in the management of patients with chronic kidney disease: A systematic review. Nephrol Dial Transplant 2012;27(1):276-92.

8. Viktil KK, Blix HS. The impact of clinical pharmacists on drugrelated problems and clinical outcomes. Basic Clin Pharmacol Toxicol 2008;102(3):275-80.

9. Gulec S, Anderson GJ, Collins JF. Mechanistic and regulatory aspects of intestinal iron absorption. Am J Physiol Gastrointest Liver Physiol 2014;307(4):G397-409.

10. Lacy CF, Armstrong LL, Goldman MP, Lance LL. Lexi-Comp's Drug Information Handbook 2010-2011: A Comprehensive Resource for All Clinicians and Healthcare Professionals. $19^{\text {th }}$ ed. Hudson: Lexi-Comp; 2010 . 